\title{
Grupo de Teatro Popular de Sansinena. Nuevos abordajes posibles para su análisis
}

\section{Clarisa Fernández}

El pueblo de Sansinena se encuentra en el Partido de Rivadavia, al noroeste de la Provincia de Buenos Aires, Argentina. Fue fundado en 1913 en las inmediaciones de las vías del Ferrocarril Oeste, transporte que le permitió al pueblo trasladar materiales de agricultura, ganadería y comercio, así como también mantener una conexión fluida con la Ciudad de Buenos Aires y pueblos aledaños.

Según datos del último Censo Nacional de Población, Hogares y Viviendas del Instituto Nacional de Estadísticas y Censos (INDEC), realizado en el año 2010, Sansinena cuenta con aproximadamente 650 habitantes, incluyendo parajes rurales cercanos. En sus 7 cuadras por 7 cuadras, cobija una delegación municipal, un colegio primario y secundario (éste instalado hace pocos años), la iglesia, el cuartel de bomberos voluntarios, la Casa de Cultura, un club, un centro recreativo y un museo. La mayor parte de los residentes se dedica a las actividades de agricultura, ganadería o comercio. Los caminos todavía son de tierra y el servicio de agua potable no ha sido completamente instalado. La población es en su mayoría de edad avanzada, ya que muchos de los jóvenes han emigrado en busca de oportunidades laborales o por estudio.

Existieron sucesos que marcaron fuertemente la vida del pueblo, el que tiene una historia de desapariciones y abandonos. Sansinena pasó de ser uno de los parajes del Partido de Rivadavia con mayor cantidad de población a mediados del siglo XX - donde se concentraban grandes estancias proveedoras de trabajo, la fábrica de queso y el correo central - a convertirse en un pueblo olvidado, a raíz de la quiebra o desaparición de estos motores productivos. Los cambios en los sistemas de cosecha y siembra que lentamente se concentraron en la producción de soja, la merma de la actividad 
propiamente ganadera que empezó a generar pérdidas en vez de ganancias, la desaparición de las grandes estancias y la quiebra de las fábricas produjeron un descenso paulatino pero progresivo de habitantes que partieron hacia localidades cercanas. En el año 2001 se desbordó el Río V (que recorre el centro de la Provincia de San Luis y el sur de la Provincia de Córdoba), generando la inundación más recordada por los habitantes del lugar como el momento en que "el pueblo casi desaparece bajo el agua, pero nosotros lo salvamos" (Bello, Entrevista). Las inundaciones de ese año son recordadas como el hecho más traumático de la historia local, ya que debieron ser evacuados niños y ancianos, mientras sólo un número de pobladores se quedaron tratando de evitar que el agua entrara al pueblo, generando canales de contención.

El Grupo de Teatro Popular de Sansinena nació en el año 2006 cuando María Emilia de la Iglesia, una habitante del pueblo que había estudiado teatro y comunicación en la ciudad de La Plata, ${ }^{1}$ volvió a su pueblo y decidió organizar un pequeño grupo de teatro. La última actividad teatral en Sansinena la había desarrollado su padre, Osvaldo de la Iglesia, 17 años antes, a través de un grupo de teatro vocacional que nucleó aproximadamente a 15 actores. La gestación del grupo tuvo sus conflictos, ya que los sansinenses estaban reticentes a reunirse; muchos admiten haber quedado atomizados luego de las inundaciones, cada uno en su casa y sin participar de ninguna actividad en común, a pesar de lo pequeño del lugar. Durante los primeros años (20062008) el grupo de teatro representó obras de dramaturgos consagrados como Los árboles mueren de pie, de Alejandro Casona, o La zapatera prodigiosa, de Federico García Lorca. Las lógicas de producción de estas obras respondían a dinámicas de funcionamiento tradicionales de los grupos de teatro independiente, en donde la directora concentraba las tareas de mayor responsabilidad en cuanto a la adaptación del guión, la elección de los personajes y las decisiones de la puesta en escena. Se trató de puestas con escenografía elaborada por los propios vecinos, en donde participaron aproximadamente quince personas, la mayoría de ellas previamente vinculadas con el teatro, a partir de la actividad que había realizado Osvaldo de la Iglesia en el pueblo.

A partir del 2008 empezaron a pensar en crear una obra que contara la historia del pueblo y así ingresaron al mundo del teatro comunitario. Por los caminos de mi pueblo fue la primera obra que realizaron bajo el método de la creación colectiva, a través de los aportes de los vecinos de sus anécdotas, experiencias, material documental, fotos y recuerdos. Lentamente el relato fue adquiriendo una coherencia y De la Iglesia se encargó de construir un hilo conductor por medio de un guión. La obra contaba con escenas sobre 
el surgimiento del pueblo, personajes paradigmáticos de la historia local, referencias al ferrocarril y su desaparición, el drama de las inundaciones y situaciones de la cotidianidad e idiosincrasia de Sansinena. El relato iba desde la fundación del pueblo en el año 1909 hasta el año 2001, cuando las inundaciones aislaron totalmente a Sansinena. La última escena, de fuerte tono emotivo, presentó a los niños y niñas del pueblo vestidos con guardapolvos y dispuestos frente al público como preparando la oración a la bandera argentina. El último parlamento fue el juramento, en donde "los niños del pueblo" prometieron comprometerse con la lucha para que el pueblo salga adelante y resista frente a los discursos que bregan por la desaparición de los pequeños pueblos.

Es importante destacar que las dos primeras obras mencionadas (Los árboles mueren de pie y La zapatera prodigiosa) pertenecen al primer ciclo de producciones del grupo, en donde las lógicas de creación utilizadas no reflejaban todavía los modos de construcción del teatro comunitario (que parte de creaciones colectivas). Fue con la tercera obra del grupo (Por los caminos de mi pueblo) en donde se afianzaron las modalidades de creación colectiva y comunitaria, con la incorporación de más vecinos al grupo y la transformación de los métodos de producción teatral. Las representaciones del grupo se realizan mayormente en el pueblo mismo (donde el público son los mismos vecinos y vecinas del lugar), sin embargo viajan regularmente hacia localidades cercanas para participar de eventos o dar a conocer sus obras.

Si bien el Grupo de Teatro Popular de Sansinena tiene particularidades específicas que lo diferencian de los otros grupos de teatro comunitario (ligadas fundamentalmente al ámbito geográfico rural en donde se desarrolla la actividad), forma parte de la Red Nacional de Teatro Comunitario desde el año 2008. A partir del intercambio con otros grupos se consensuó que el Partido de Rivadavia fuera la sede del Noveno Encuentro Nacional de Teatro Comunitario, que se desarrolló en octubre del año 2011. Esta decisión se vinculó con la reciente conformación del Grupo de Teatro Comunitario de Rivadavia, en donde la experiencia pionera de Sansinena funcionó como agente multiplicador.

Durante el año 2008, De la Iglesia convocó a los vecinos y vecinas de un pueblo cercano, González Moreno, que comenzó a producir obras de creación colectiva basadas en anécdotas de los vecinos del pueblo. Pero fue a partir del año 2009 que la directora y un grupo de vecinos de Sansinena y González Moreno aunaron fuerzas para convocar a personas de otros pueblos del Partido de Rivadavia y conformar así un gran grupo de teatro comunitario 
de todo el Partido. Con ese objetivo se comenzaron a coordinar grupos en Roosevelt, Fortín Olavarría, América y San Mauricio, de modo articulado con los de Sansinena y González Moreno. Gracias al trabajo conjunto que realizaron los vecinos de estos pueblos, en el año 2010 se estrenó en San Mauricio la obra La historia se entreteje desde abajo y se cambia desde la comunidad. $^{2}$

Varios proyectos y emprendimientos surgieron impulsados por la actividad teatral: la recuperación y restauración de la estación de tren abandonada del pueblo de González Moreno, donde se inauguró el centro cultural "Sobrerrieles marcha la cultura"; la conformación de un grupo de pintores comunitarios y la instalación de talleres de oficio (carpintería, herrería, tornería, textil).

\section{Posibles abordajes}

Como fenómeno social, el surgimiento del Grupo de Teatro Popular de Sansinena es interesante desde varias perspectivas. Por un lado, las instancias del proceso de construcción de obra abren las puertas al inexplorado mundo de la memoria colectiva, a las tensiones y conflictos que presenta la negociación sobre los sentidos del pasado, a la decisión sobre qué acontecimientos contar y qué relevancia se le dará a los sucesos que forman parte de la historia del pueblo. Por otro lado, otro posible análisis podría abordar cuestiones referidas a las lógicas de funcionamiento del grupo, tanto hacia el interior como hacia el exterior del mismo, destacando sentidos construidos en torno a estas lógicas y a su implicancia en la vida cotidiana de los vecinos.

Es un buen punto de partida pensar en las características de este teatro y en una posible clasificación o diferenciación, en relación a otros fenómenos teatrales y culturales con los cuales se pueden identificar rasgos en común. ¿Estamos hablando de activismo artístico? ¿Qué rasgos definen al teatro comunitario como tal y lo diferencian de otros grupos artísticos colectivos? ¿Qué elementos retoman de prácticas anteriores y cómo las resignifican? ¿Qué marco contextual está de fondo para que el surgimiento de este grupo haya tenido lugar?

Serán fundamentales a la hora de ensayar algunas respuestas a estas preguntas las categorías esbozadas por autores como Raymond Williams, Ana Wortman, Ana Longoni y diversos analistas del campo de los estudios culturales. Porque como cualquier práctica cultural, el teatro comunitario construye un discurso que postula ciertos principios ideológicos, genera 
prácticas determinadas y se inserta desde el ámbito cultural hacia otras esferas de lo social, con las que se encuentra íntimamente imbricado.

\section{La construcción de un espacio ¿alternativo?: estética y acción política}

Mucho se ha dicho sobre las manifestaciones colectivas que tuvieron lugar después de la crisis argentina del 2001. Autores como Svampa, Schuster, Pérez y otros han estudiado cómo diversos sectores de la población "tomaron la palabra" para convertirse ellos mismos en portavoces, alejándose de la costumbre delegativa y representativa. En un trabajo publicado en el 2009, Ana Wortman escribe y compila una serie de artículos en los que se analiza el surgimiento de nuevos actores dentro del ámbito de la cultura y la transformación de los sentidos sobre la participación y la acción colectiva. El concepto de gestión cultural hace referencia a un nuevo modo de concebir la acción política, que se vería reflejado en la actividad de nuevas organizaciones culturales que proponen una articulación alternativa entre arte y política a la de las vanguardias de los 60 y 70 (Wortman, "Sociedad").

La autora sugiere que en el contexto del post 2001 emerge la cultura como un espacio generador de significados alternativos, en donde se destacan valores ligados a la solidaridad, antineoliberales, cooperativos, etc. Traemos a colación esta reflexión porque los pocos autores que han trabajado con teatro comunitario (Proaño Gómez, Bidegain, Rosemberg) coinciden en señalar el contexto del post 2001 como el momento de "explosión" del teatro comunitario en el país. Y esto es cierto, ya que a partir del año 2002 los directores de los dos grupos pioneros - Adhemar Bianchi de Catalinas Sur y Ricardo Talento del Teatral Barracas - iniciaron una "gira" por la Provincia, impulsada por el Programa Cultural en Barrios del Gobierno de la Ciudad de Buenos Aires, por medio de la cual convocaban profesionales del teatro que puedan dirigir futuros grupos en la Provincia. Es importante entonces, resaltar que si bien fue fundamental el contexto de apertura y ebullición política que caracterizó al post 2001, muchos de los grupos surgieron al calor del apoyo estatal y de la iniciativa de los "entusiasmadores" ${ }^{3}$ a través de la Carpa Itinerante.

Estos nuevos "espacios de resistencia" de los que habla Wortman se caracterizarían por organizarse de forma más horizontal —oponiéndose a las jerarquías culturales-, democrática e igualitaria, siendo común la práctica asamblearia e informal en la toma de decisiones. Estarían ligados a una búsqueda de nuevos estilos de vida, cuestionando las estructuras burocráticas (Wortman, "Espacios"). Dentro de la misma línea, otros autores desarrollan sus estudios en torno a diversas experiencias. Así, Denise Osswald trabaja 
con los centros culturales autogestionados surgidos en el contexto del post 2001, a los que identifica como nuevos espacios de sociabilidad donde se producen sentidos opuestos a los neoliberales de los años 90, cuyos protagonistas pertenecen en su mayoría a sectores de clase media. La autora destaca que estos emprendimientos se alejan de las dinámicas político partidarias $\mathrm{y}$ asistencialistas, para generar un proyecto social integrador que recupera tradiciones y luchas pasadas.

Por su parte, Uhart y Molinari plantean que se generó luego de la crisis un nuevo modo de acercarse a la política, distanciado de los viejos militantes de los 70, de los partidos políticos y los sindicatos, mientras que Guillermo Martín Quiña afirma que

referimos 'lo político' en el arte a una práctica artística que se plantea consciente y expresamente el abordaje de cuestiones de la realidad social y que busca incidir así en ella, mediante los materiales que utiliza, sus lugares de exposición, sus contenidos y formatos, etcétera. (218)

Veremos luego si esta definición de "lo político" en el arte puede pensarse en la experiencia del Grupo de Teatro Popular de Sansinena y si las características otorgadas por estos autores a los nuevos colectivos artísticos surgidos en el post 2001 comparten o no elementos con nuestro objeto.

\section{¿De qué hablamos cuando hablamos de teatro comunitario?}

Si bien se ha definido a partir de las primeras sistematizaciones realizadas sobre teatro comunitario como un teatro de vecinos para vecinos (Bidegain), los más de cincuenta grupos que existen en el país adquieren dinámicas, lógicas de funcionamiento, estrategias de negociación y visiones sobre el producto estético diferentes. Basta pensar en el grupo Catalinas Sur (primer grupo de teatro comunitario nacido en 1983), con sus grandes producciones internacionales, sus más de 300 miembros y numerosos premios recibidos, para notar las diferencias con los restantes grupos (salvo contadas excepciones como el grupo de Barracas, que es el segundo grupo pionero, surgido en 1996). Las trayectorias de cada grupo difieren enormemente y se hace dificultoso encontrar puntos en común, más allá de que pertenecen a la Red Nacional de Teatro Comunitario y que comparten un discurso anti-neoliberal que resalta los valores modernos de solidaridad, fraternidad e igualdad. Estas diferenciaciones que nos impiden avanzar en una generalización se profundizan e intensifican en el caso de los grupos que pertenecen a comunidades muy pequeñas, como Sansinena, en donde las historias, las prácticas y los sentidos adquieren matices más tradicionalistas que en las grandes ciudades. 
Por estos motivos es válido preguntarse: ¿qué tipo de espacio construye el Grupo de Teatro Popular de Sansinena? ¿Qué elementos comparte con otros espacios artísticos colectivos? ¿Qué factores de cambio y de continuidad establecen dentro de las dinámicas propias del pueblo? Si bien los interrogantes son muchos y muy complejos, intentaremos ensayar algunas reflexiones que nos permitan comenzar a pensar en posibles respuestas.

Una forma posible de pensar el teatro comunitario como fenómeno es la perspectiva de los movimientos sociales. En particular desde la perspectiva que analiza los movimientos sociales en relación a la conformación de nuevas identidades (Touraine, Melucci, Offe), hablamos de un colectivo que comparte un objetivo común que es portador de una demanda al sistema político y que construye su identidad en relación a otro, del cual se diferencia. Es interesante esta vertiente en cuanto retoma elementos de la memoria, de un pasado compartido en la construcción de la nueva identidad colectiva, como proceso conflictivo y complejo. Incluso es tentador el adoptar esta visión por la relación ineludible que encontramos con las ruedas de memoria que utiliza el teatro comunitario en su práctica y el rol de la experiencia compartida en la conformación de las nuevas identidades.

Por otro lado, vemos que el Grupo de Teatro Popular de Sansinena adquiere rasgos característicos de estos movimientos, como son la organización horizontal, la práctica asamblearia, las decisiones conjuntas, los valores de solidaridad y cooperación, entre otros. Sin embargo, un elemento fundamental que define a estos movimientos está ausente: la demanda al sistema político, el que puede identificarse, según algunas vertientes que estudian movimientos sociales — como la postestructuralista (Laclau, Arditi, Rancière)— como el enemigo/antagonista frente al cual se busca la reivindicación. Retomando estos postulados a la luz del Grupo de Teatro Popular de Sansinena, las ausencias son notables. No sólo no encontramos una demanda concreta al sistema político (trabajo, educación, derechos sexuales), sino que además no está delineado un antagonista. Reconocemos un repertorio de acción en la actividad teatral e incluso cuestionamientos o denuncias a través de los parlamentos de las obras sobre la falta de asfalto o infraestructura, pero no se presenta tal como estos autores lo están pensando una demanda al sistema político institucional democrático.

Esta reflexión nos lleva a plantear al grupo de teatro como un espacio que se encuentra por fuera de las instituciones, pero que está en articulación con ellas, no sólo porque existen intercambios de recursos materiales y simbólicos, sino también porque se mantienen constantes negociaciones 
con autoridades y sectores de poder, ya se trate de luces para el escenario, de un espacio en un programa turístico o en un evento artístico. Sería errado establecer una distancia entre el teatro y las instituciones o sectores de poder, ya que existe entre ellos una relación conflictiva, de mutua colaboración, que se tensiona permanentemente.

\section{Activismo artístico, formaciones y preguntas pendientes}

Revisemos los rasgos fundamentales del lenguaje teatral comunitario. Se trata de una obra que relata acontecimientos de la historia del pueblo y que emplea elementos del grotesco, el sainete, la sátira y el absurdo. La obra de Sansinena, con su particular historia de inmigrantes y códigos pueblerinos, utiliza el humor para reflexionar, como lo hacen la mayoría de los grupos de teatro comunitario. De esta forma se estereotipan y exageran las representaciones de los personajes y nunca se apela al drama. Se busca la identificación con el público, que es el mismo vecino que fue protagonista de esa misma situación en algún momento de su vida y que ve recreados en el escenario sus propios anhelos, expectativas, memorias, miedos y frustraciones. Los vecinos lloran al ver la escena de las inundaciones, porque recuerdan las noches en vela luchando para que el agua no entrara al pueblo. También se emocionan cuando del parlante se escucha la bocina del tren o cuando se recrea la inauguración de alguna institución.

Los sansinenses se juntan todos los viernes en la estación para seguir creando y ensayando la obra. Llevan el mate, alguna torta o bizcocho casero y la guitarra. Vecinos de 10 a 90 años se reúnen en ese espacio común y construyen un relato que es el propio. Se organizan cuando viajan, consiguen transportes y aquellos que no participan colaboran con el armado de escenografía, vestuario o lo que se necesite para la puesta. Actualmente son 40 personas - de 650 que es la población total - las que conforman el grupo de teatro. Lentamente van adquiriendo legitimidad y los pobladores se van acercando unos a otros, se retoman los lazos perdidos, se prende la música y las luces y Sansinena vuelve a tener vida teatral y cultural. De este encendido colectivo surgen otros proyectos a la luz de los resultados que el teatro les ha traído: un lugar en el mapa, la visibilización de la comunidad, un nuevo horizonte de expectativas.

Por primera vez en su historia, el Partido de Rivadavia fue sede de un encuentro nacional, del que participaron miles de personas que deambularon durante los tres días que duró el evento por los distintos pueblos del Partido, viendo y haciendo teatro. ${ }^{4}$ El Grupo de Teatro Popular de Sansinena 
se convirtió así en la primera organización social del lugar. Ahora bien, sería interesante reflexionar sobre esta experiencia a partir de algunas categorías que pueden sernos útiles para comprender y profundizar en las características, posibles potencialidades y limitaciones de esta práctica.

Cuando se hace alusión al activismo artístico, que puede ser llamado de otras maneras, como activismo cultural o militancia artística, se está hablando de una articulación entre la actividad artística y la acción política. Los trabajos que referenciamos anteriormente de Wortman, Osswald y Uhart y Molinari establecían un lazo entre ciertas experiencias artísticas del post 2001 como centros culturales o asambleas barriales con organizaciones o movimientos políticos, a su vez que los identificaban con el surgimiento de nuevas subjetividades.

Hacia fines de los 90, y casi simultáneamente con el surgimiento de los movimientos piqueteros, se conformaron varios colectivos artísticos que hasta el día de hoy continúan llevando adelante prácticas de protesta en el espacio público, a fin de apoyar o deslegitimar a alguna situación/actor. Estos grupos utilizan algunos elementos que también podemos encontrar en el teatro comunitario, como la estética y el humor para representar una situación cuestionada. Tanto el Grupo de Arte Callejero (GAC), como el grupo Etcétera (por citar sólo algunos) surgieron en 1997; ellos intentan promover una percepción renovada de la práctica política, a través de un arte de acción que rechaza el academicismo e innova reapropiándose de prácticas y vanguardias artísticas anteriores (Moglia y Vázquez).

Moglia y Vázquez cuestionan la relación entre activismo artístico y acción política, y presentan una serie de interrogantes que parten de una incomodidad para pensar en la conjunción de estos dos elementos. Los autores analizan este vínculo en relación a la institucionalización de sus prácticas, la relación con el mercado y la utilización del espacio público. Queda pendiente la pregunta sin contestar: ¿pueden estos grupos propiciar o ligarse a un gesto revolucionario?

Por su parte, Svampa define la modalidad de acción del activista cultural, enlazada con lo que son los grupos de afinidad, colectivos que suelen adoptar una dimensión a la vez política y cultural ("Movimientos"). Para la autora, en estos grupos la acción directa y lo público aparecen como un lugar desde el cual se construye identidad. Si bien en un comienzo sitúa al activista cultural como mero "acompañante" de los movimientos sociales, luego afirma que no son sólo actores de reparto sino protagonistas en las luchas anti-neoliberales. 
Queda entonces una serie de preguntas planteadas: ¿podrían los vecinos del Grupo de Teatro Popular de Sansinena considerarse activistas culturales? ¿Qué tipo de redes genera el teatro en el pueblo? ¿Qué elementos toman de las experiencias pasadas? Intentaremos, en el último apartado del trabajo, comenzar a pensar estas cuestiones, teniendo en cuenta que los interrogantes son complejos y sólo ensayaremos puntas a partir de las cuales seguir profundizando.

\section{Formaciones y tradición selectiva}

A lo largo de este trabajo hemos desarrollado una serie de reflexiones sobre la clasificación y caracterización del grupo de teatro de Sansinena, con el fin de comprender su especificidad. Abordamos el análisis de otros colectivos artísticos que comparten ciertos elementos con esta práctica, pero aun así no hemos podido construir un modo de clasificar - sin clausurar-a esta actividad.

En Sociología de la comunicación y el arte, Raymond Williams se encarga de estudiar las relaciones que se establecen en el mundo del arte, sus instituciones, el mercado y los artistas. Si bien su análisis se enmarca en otro momento histórico y sus clasificaciones son ricas pero estructuradas en cuanto a los límites que establece para cada una de ellas, hay una categoría que es interesante retomar para el estudio de nuestro objeto: el de formaciones.

El autor denomina formaciones al tipo de organización que hace referencia a un grupo de artistas que no tienen una afiliación, sino que se asocian, comparten prácticas y "sus relaciones sociales inmediatas no se distinguen fácilmente de las de un grupo de amigos comunes" (Sociología 61). En Marxismo y literatura, Williams también retoma el concepto y añade que "estos movimientos y tendencias tienen una influencia significativa y a veces decisiva en la vida de una cultura, y presentan una relación variable y a veces solapada con las instituciones formales" (161).

La perspectiva de Williams sobre las formaciones es interesante para pensar en el Grupo de Teatro Popular de Sansinena, ya que nos permite comenzar a delinear un tipo de colectivo cultural que no se vea limitado por las estructuras que encasillan a otras prácticas colectivas, como los movimientos sociales. Por otro lado, podemos identificar aquellas experiencias previas de las cuales se nutre el teatro comunitario teniendo como bastión la categoría de tradición selectiva, que nos permite establecer lazos con prácticas del pasado, del cual ciertos significados son seleccionados y acentuados pero otros rechazados (Marxismo). 
Dentro de estas experiencias previas, encontramos ciertas tendencias teatrales que han nutrido la fuente de conocimientos del teatro comunitario, como el teatro callejero y popular de los años 80 (el teatro callejero Héctor Alvarellos, el Movimiento de Teatro Popular - MOTEPO — del cual surgieron los grupos pioneros de teatro comunitario Catalinas Sur y Circuito Teatral Barracas, el Teatro de la Libertad de Dacal, etc.). Estos grupos comparten elementos con el teatro comunitario, como la utilización del espacio público, la transformación de la relación actor-espectador, el ejercicio de la memoria a través de la reapropiación de la literatura popular con sus fábulas y leyendas, el trabajo con la comunidad, entre otras.

Cuando hablamos de una tradición selectiva, decimos que no todo se trae al presente; depende en buena medida de los sentidos que los vecinos busquen reivindicar y los que no. En la obra de teatro de Sansinena, en relación a las experiencias teatrales previas, se encuentran presentes muchos de los componentes nombrados en el párrafo anterior (la resignificación del espacio público, la transformación de la relación entre el actor y el espectador, etc.) pero en el nivel de las temáticas, vemos que hay acontecimientos que parecerían fundamentales recordar de la historia argentina y en la obra no están presentes, como es el caso de la última dictadura militar argentina (19761983). Por otra parte se relatan las inundaciones del 2001, las situaciones cotidianas de la vida del pueblo, el ferrocarril y otros hechos que marcaron la vida de los habitantes.

\section{Diferencias y similitudes con experiencias actuales}

En los casos de GAC y ETC, observamos claramente que el trabajo de intervención artística que llevan a cabo estos colectivos se inscribe tanto en la temática, que en general es de denuncia, como en las modalidades de acción. Si bien estos grupos buscan generar una práctica renovada de la política, utilizando el humor, la ironía y la burla, identificamos en su discurso un objetivo claro de confrontación con ciertos postulados de la economía capitalista y sus modos de vida (representados, por ejemplo, en la cadena de comidas rápidas McDonald's). Una vez establecidos los objetivos de confrontación, idean una estrategia de intervención artística en pos de generar nuevos sentidos sobre ese objeto/situación/actor.

Aquí está la primera diferencia con la práctica comunitaria, en cuanto no existe allí un objetivo de confrontación, sino más bien de integración. Pareciera ser que el epicentro de transformación y de construcción de sentido no está en el mensaje que se intenta transmitir como grupo, en la temática o 
contenido de la acción, sino en su proceso organizativo. Está estudiado por Proaño Gómez de qué modo el teatro comunitario genera prácticas que desde su lógica combaten el individualismo y la propiedad privada (valores básicos del sistema neoliberal), a través de una actividad que no impone restricciones de ningún tipo para participar, que no busca el éxito comercial, que difunde la idea de solidaridad, la reconstrucción de lazos sociales y la propiedad colectiva ("Estética", "Teatro"). El hecho de que los grupos sean autogestivos importa cuestiones que alimentan esta dinámica anti-corporativa, aunque no podemos desconocer que también atraen conflictos, ya que no todos los grupos de la Red tienen el mismo criterio a la hora de seleccionar sus apoyos económicos y buscar subsidios.

Por otra parte, el teatro comunitario de Sansinena se diferencia de estos grupos en la medida en que no genera una práctica de reflexión especifica sobre la relación que establece con las instituciones, como sí lo han hecho los colectivos artísticos de vanguardia del 68 (Longoni). Y aquí es necesario introducir una cuestión fundamental para entender el proceso llevado a cabo por el teatro en el pueblo de Sansinena: el tema del liderazgo. El rol que desempeña María Emilia de la Iglesia, como coordinadora del grupo de Sansinena pero también del Partido de Rivadavia, está enlazado con su formación académica y política en diversas organizaciones de la ciudad de La Plata, lo que le permite muchas veces reflexionar o tomar decisiones que inevitablemente estarán embebidas de estas experiencias y que, en gran parte, difieren de las del resto de los vecinos.

A pesar de las dificultades que se generan a la hora de delegar responsabilidades, lo que acarrea un sinnúmero de problemas por la sobrecarga de tareas sobre la directora, existe de parte de la coordinación un reconocimiento de este problema y un intento de poner en marcha alternativas para su solución. En relación a la reflexión sobre la propia práctica, entramos en un terreno aún inexplorado que es el de las motivaciones y sentidos que los vecinos y las vecinas de Sansinena le otorgan a la práctica teatral. ${ }^{5}$

El Grupo de Teatro Popular de Sansinena se enmarca dentro de una tendencia que viene creciendo en los últimos años, que promueve la asociación entre personas con metas culturales, sin fines de lucro y fomentando la participación de toda la comunidad. La Red Nacional de Teatro Comunitario, ${ }^{6}$ a su vez, es parte de la Red Latinoamericana de Arte y Transformación Social, ${ }^{7}$ asociación que nuclea diversas expresiones que buscan a través del arte transformar de alguna manera la sociedad. 
Retomando las reflexiones iniciales del trabajo, es importante destacar la importancia del contexto en el cual estas experiencias tienen lugar: la crisis del 2001 como telón de fondo del surgimiento de las asambleas barriales y los centros culturales autogestionados, fenómenos en su mayoría protagonizados por las clases medias. En un texto de Alfredo Palacios Garrido, el autor encuentra rasgos en común en diversas expresiones artísticas a las que denomina arte comunitario: la convicción de que la creatividad posee en sí una fuerza real de transformación social; el desacuerdo con las jerarquías culturales; prácticas que buscan una implicación en el contexto social por sobre un fin estético, ${ }^{8}$ todos los cuales fomentan la participación de la comunidad y transforman el concepto moderno de la obra artística por su carácter procesual.

Por último señalaremos la importancia que está adquiriendo este tipo de emprendimientos culturales colectivos, puntualizando la experiencia de Pueblo hace cultura. Este proyecto lucha por la aprobación de la Ley de Puntos de Cultura, en donde se plantea que el $0,1 \%$ del presupuesto nacional se destine al fortalecimiento de organizaciones culturales comunitarias, de arte autogestivo e independiente. Los colectivos culturales que forman parte de este proyecto presentaron un documento:

Algunos de los grupos que aquí participamos nos reconocemos como independientes o apartidarios. Otros nos referenciamos en distintos espacios políticos, con miradas sobre la historia y el presente que no siempre son coincidentes. A partir de esta diversidad asumimos el desafío, siempre complejo, de construir un colectivo que se articule a partir de lo común, de aquello que nos encuentra y que todos compartimos. Esto nos obliga a trascender y superar nuestras miradas particulares, para asumir una identidad colectiva. ("Documento de presentación")

Situamos el caso del Grupo de Teatro Popular de Sansinena dentro de este movimiento cultural que nuclea, en un nivel más amplio, organizaciones culturales latinoamericanas, y, a nivel micro, experiencias colectivas del país. Sin embargo, aún existen grandes diferencias en cómo estas prácticas organizativas impactan en los grupos de teatro comunitario de las ciudades y cómo lo hacen en los pueblos. Las lógicas tradicionalistas muchas veces rigen las prácticas de los pequeños pueblos del interior, que reafirman valores ligados al trabajo, la familia, las buenas costumbres, la religiosidad, etc. En el caso de Sansinena, la práctica teatral comunitaria está construyendo una 
nueva lógica, en donde los habitantes se organizan, a pesar de sus diferencias, en pos de un objetivo común: el teatro.

Si bien los proyectos organizados desde los centros urbanos tardan más en llegar a estos pueblos, el teatro comunitario de Sansinena —a través de la presencia de María Emilia de la Iglesia y algunos de sus compañeros en las reuniones de la Red Nacional - ha logrado convertirse en la sede del Noveno Encuentro Nacional de Teatro Comunitario, que se llevó a cabo en octubre del año 2011. Esto se convierte en una prueba de que si bien no podemos catalogarlo como un movimiento social, sí existe una organización creciente y duradera, ya que los vecinos han decidido asociarse y construir nuevas miradas sobre el pasado y el presente, generando transformaciones en los sentidos y las prácticas de sus habitantes, apostando por un proyecto colectivo de más de 200 miembros y dando lugar a una experiencia inédita en el Partido de Rivadavia.

\section{IDIHCS (Instituto de Investigaciones en Humanidades y Ciencias Sociales) Universidad Nacional de La Plata/ Conicet}

\section{Notas}

1 Ciudad capital de la Provincia de Buenos Aires.

2 San Mauricio tiene actualmente quince habitantes, cuenta con una plaza y está rodeado de estructuras semi-destruidas, otrora símbolos de prosperidad del pueblo. Fue necesario dotar al pueblo de la infraestructura necesaria para poder llevar adelante la representación. Participaron vecinos de seis pueblos del Partido, y tuvo un público de cinco mil personas que viajaron especialmente para la función. El evento se logró gracias a la colaboración de innumerables instituciones y organismos estatales que colaboraron con recursos, infraestructura y elementos técnicos necesarios para la puesta en escena y para la contención del público (Fernández). Para información sobre el evento y público que asistió en páginas de diarios digitales, ver "Presentan obra de teatro comunitario en un pueblo casi fantasma", "Domingo 31 de octubre 2da Función del Teatro Comunitario en San Mauricio" y Teatro comunitario de Rivadavia.

3 Suele decirse entre los participantes de teatro comunitario que los "entusiasmadores" son aquellos que, habiendo atravesado la experiencia de participar en algún grupo de teatro comunitario, se encargan de transmitir la experiencia en otros lugares.

4 El Noveno Encuentro Nacional de Teatro Comunitario se realizó los días 8, 9 y 10 de octubre en el Partido de Rivadavia. Contó con 6 sedes, en donde tuvieron lugar más de 21 espectáculos teatrales y 21 grupos de teatro comunitario hicieron sus espectáculos. Para más información ver: http:// encuentronacionalenrivadavia.blogspot.com.ar/

5 Está bien claro que De la Iglesia considera el teatro comunitario como una herramienta de cambio social, como lo ha expresado en las entrevistas realizadas durante el 2010: "Acá en Sansinena y en G. Moreno el teatro comunitario se ha transformado en un motor, pero que si solo se queda con el teatro no tiene mucha perspectiva de crecimiento. Lo que estamos haciendo ahora es vincularnos con las instituciones (escuela, sala, etc.)" (De la Iglesia). Pero los participantes del teatro comunitario, ¿qué 
sentido le otorgan a su práctica? ¿Se consideran activistas culturales, en el sentido de Svampa? Estos interrogantes aún no tienen respuestas, ya que implican un estudio aparte.

6 Está conformada por más de 40 colectivos de teatro comunitario de todo el país, con el objetivo de construir un espacio de intercambio de experiencias entre los grupos (Red Nacional).

7 Para más información, ver su página web: http://www.artetransformador.net/sitio/.

8 Aquí es necesario anotar que si bien en el Grupo de Teatro Popular de Sansinena la envergadura de los impactos de la práctica teatral resulta en un señalamiento mayor del proceso de producción por sobre las cuestiones estéticas, no sucede esto en todos los grupos. Algunos directores enfatizan la importancia del cuidado estético de la obra como uno de los elementos fundamentales a cuidar en actividad.

\section{Bibliografía}

Alvarellos, Héctor. Teatro callejero en la Argentina (1982-2006). De lo visto, vivido y realizado. Buenos Aires: Ediciones Madres de Plaza de Mayo, 2007. Impreso.

Arditi, Benjamín. "Rastreando lo político". Revista de Estudios Políticos 87 (eneromarzo 1995): 333-51. Impreso.

Argentina. Instituto Nacional de Estadística y Censos. Censo 2010 Argentina. Web. $<$ http://www.censo2010.indec.gov.ar/>

Bello, Edith. Entrevista personal. Junio 2010.

Bello, Edith y María Emilia de la Iglesia. Sansinena existe. Retazos de memoria. Tejidos de futuro. Buenos Aires: Municipalidad de Rivadavia, 2009. Impreso.

Bidegain, Marcela. Teatro comunitario, resistencia y transformación social. Buenos Aires: Atuel, 2007. Impreso.

De la Iglesia, María Emilia. Entrevista personal. Marzo 2010.

"Documento de presentación - Pueblo hace cultura". Red latinoamericana de arte para la transformación social. Web. <http://www.artetransformador.net/ sitio/images/biblio/documento_presentacion_pueblo.pdf $>$

"Domingo 31 de octubre 2da Función del Teatro Comunitario en San Mauricio". Master News. 26 de octubre de 2010. Web. <http://www.masternews.com.ar/index.php?option $=$ com_content $\&$ view $=$ article $\& i d=5675$ :domingo-31-de-octubre-2da-funcion-del-teatro-comunitario-en-sanmauricio\&catid $=42$ :el-distrito\&Itemid $=90>$

Fernández, Clarisa. "Cuando la historia se hace tierra. Teatro comunitario en San Mauricio". Aletheia 1.1 (octubre de 2010). Web. <http://www.aletheia.fahce.unlp.edu.ar/numeros/numero-1/numeros/numero-1/clarisa-fernandez.cuando-la-historia-se-hace-tierra.-en-teatro-comunitario-en-san-mauricio>

Laclau, Ernesto. Nuevas reflexiones sobre la revolución de nuestro tiempo. Buenos Aires: Nueva Visión, 1990. Impreso.

" "Tesis acerca de la Forma Hegemónica de la Política". Hegemonía y al- 
ternativas políticas en América Latina. Comp. J. Labastida Martin Del Campo. México: Siglo XXI, 1985. 19-44. Impreso.

Laclau, Ernesto y Chantal Mouffe. Hegemonía y estrategia socialista. Buenos Aires: FCE, 2004 [1987]. Impreso.

Longoni, Ana y Mariano Mestman. Del Di Tella a "Tucumán Arde". Vanguardia artística y política en el 68 argentino. Buenos Aires: Eudeba, 2008. Impreso.

Melucci, Alberto. "Asumir un compromiso: identidad y movilización en los movimientos sociales". Zona Abierta 69 (1994): 153-80. Impreso.

Moglia, Mercedes y Cecilia Vázquez. "El dilema del activismo artístico, o el juego humorístico de evidente y vacío". Questión 1.17 (2008). Web. <http://www. perio.unlp.edu.ar/ojs/index.php/question/article/viewArticle/471>

Molinari, Viviana y Claudia Uhart. "Trabajo, política y cultura: abriendo espacios de producción material y simbólica". Wortman. 155-74. Impreso.

Offe, Claus. Partidos políticos y nuevos movimientos sociales. Madrid: Sistema, 1992. Impreso.

Osswald, Denise. "Espacios culturales en la Argentina post 2001. La cultura como trabajo". Wortman. 91-121. Impreso.

Palacios Garrido, Alfredo. "El arte comunitario: origen y evolución de las prácticas artísticas colaborativas”. Arteterapia 4 (2009): 197-211. Impreso.

Pérez, Germán J., Martín Armelino y Federico M. Rossi. "Entre el autogobierno y la representación. La experiencia de las asambleas en la Argentina”. Schuster, et. al. 387-414. Impreso.

"Presentan obra de teatro comunitario en un pueblo casi fantasma". Terra.com. 24 de septiembre de 2010. Web. <http://entretenimiento.terra.com.ar/famosos/ presentan-obra-de-teatro-comunitario-en-un-pueblo-casi-fantasma,53f742 f90354b210VgnVCM3000009af154d0RCRD.html>

Proaño Gómez, Lola. "Estética social y la aparición de lo político. Teatro comunitario y espacio urbano". Espacios de representación. Ed. Proaño Gómez y Alicia del Campo. Cádiz: Fundación Autor, 2006. 1-12. Impreso.

. "Teatro comunitario, belleza y utopía". Teatro memoria y ficción. Ed. Osvaldo Pelletieri. Buenos Aires: Galerna, 2005. 265-77. Impreso.

Quiña, Guillermo Martín. "Cultura y crisis en la gran ciudad. Los colectivos de artistas y el desarrollo de una nueva legitimidad en el arte". Wortman. 213-46. Impreso.

Rancière, Jacques. "Política, identificación y subjetivación”. El reverso de la diferencia. Identidad y política. Ed. Benjamín Arditi. Caracas: Nueva Sociedad, 2000. 145-52. Impreso.

Red Nacional de Teatro Comunitario. 2011. Web. <http://www.teatrocomunitario. com.ar/>

Rosemberg, Diego, ed. Teatro comunitario argentino. Buenos Aires: Editorial Emergentes, 2009. Impreso. 
Schuster, Federico L., Francisco S. Naishtat, Gabriel Nardacchione y Sebastian Pereyra, comps. Tomar la palabra. Estudios sobre protesta social y acción colectiva en la Argentina contemporánea. Buenos Aires: Prometeo, 2005. Impreso.

Svampa, Maristella. La sociedad excluyente. Argentina bajo el signo del neoliberalismo. Buenos Aires: Taurus, 2005. Impreso.

. "Movimientos sociales, matrices socio-políticos y nuevos escenarios en América Latina". OneWorld Perspectives 1 (2010). Web. <http://www. uni-kassel.de/hrz/db4/extern/gspg/owpDisplay.php?owp_id=9\&lang=en>

Teatro comunitario de Rivadavia. Web. $<$ http://teatrocomunitarioderivadavia.blogspot.com.ar/>

Touraine, Alain. El regreso del actor. Buenos Aires: Eudeba, 1987. Impreso.

Williams, Raymond. Sociología de la comunicación y el arte. Trad. Graziella Baravalle. Barcelona: Paidós, 1982. Impreso.

. Marxismo y literatura. Trad. Guillermo David. Buenos Aires: Las Cuarenta, 2009. Impreso.

Wortman, Ana, comp. Entre la política y la gestión de la cultura y el arte. Nuevos actores en la Argentina contemporánea. Buenos Aires: Eudeba, 2009. Impreso.

. "Espacios culturales de resistencia al discurso único, los usos de la comunicación para construir una ciudadanía nueva". Wortman. 51-61. Impreso. . "Procesos de globalización y redefinición del concepto campo artístico e intelectual". Wortman. 63-72. Impreso.

.Sociedad civil y cultura en la Argentina post crisis, la conformación de una esfera pública paralela". Wortman. 37-50. Impreso. 